\title{
Inter-Turn Stator Winding Faults Diagnosis in Three-Phase Induction Motor Fed from Imbalanced Voltage Source
}

\author{
Salam J. Mohammed and Bassim M.H. Jassim \\ Department of Electrical Engineering, College of Engineering, University of Baghdad, Jadria, Iraq \\ bassim.jassim@uob.edu.iq
}

\begin{abstract}
Quick detection of a small initial fault is important in induction machine to prevent a consequent large fault. Thus, several strategies have been presented for detection and diagnosis of different types of induction motors faults. This study presents a model for an induction motor based on Coupled Circuit Approach (CCA). This model is used to simulate an inter turn stator faults and investigate new fault detection approach when an imbalance voltage source is considered. Unlike conventional detection and diagnoses approaches which adopt symmetrical components analysis or power decomposition technique to obtain the negative sequence component of stator current, the calculation of Current Space Vector Magnitude (CSVM) is adopted. The negative sequence component of stator current is reflected as a ripple in the CSVM with peak to peak ripple proportional to the inter-turn fault severity. Therefore, the required computation burden is reduced and the detection and diagnoses become faster. Based on the Simulink model, different simulation results are used to validate the proposal.
\end{abstract}

$\underline{\text { Key words: Fault diagnosis, induction motor, stator winding faults, negative sequence current, burden, ripple }}$

\section{INTRODUCTION}

The vast majority of industrial prime movers are Induction Motors (IM's) which play a vital role in modern industry systems. About $50 \%$ of the total generated power is consumed by these motors (Thomson and Gilmore, 2003). One of the most common motor fault's is stator related which covers approximately $30-40 \%$ of the overall fault conditions in IM's (Singh and Alkazzaz, 2003). Therefore, fast detection techniques able to detect these kinds of faults at an early stage of evolution are particularly important, to avoid the catastrophic failure in industrial process (Gandhi et al., 2011). Thus, a condition monitoring system is crucial for modern industrial plants and manufacturing systems. Consequently, during the last two decades, extensive investigations have been made using many fault indicators to develop different methods that deal with electrical machines fault's diagnoses. These indicators include but not limited to linkage flux, currents, voltages, speed fluctuation and vibration (Siddique et al., 2005).

Various detection approaches have been presented for condition monitoring of electrical machines like current signature analysis which require frequency spectrum calculation for stator currents with the aid of Fast Fourier Transform (FFT) (Sharifi and Ebrahimi, 2011; Prakasam and Ramesh, 2016; Ukil et al., 2011). However, diagnoses the inter-turn stator winding faults with imbalance supply voltage condition and inherent asymmetrical machine are not ensured. At the cost of developing a mathematical model suitable to consider the inter-turn faults, an accurate inter-turn fault diagnoses is achieved using stator winding parameters identification (Abdallah and Benatman, 2017). Fuzzy logic has been used to detect stator windings faults through monitoring the motor current amplitude (Rodriguez and Arkkio, 2008). Regardless unbalance voltage source and stator winding asymmetry, motor inter-turn faults are diagnosed along with specifying the fault severity and phase location are proposed (Devi et al., 2016). This is obtained by adopting three neural networks where stator current signals are analyzed in time domain.

The negative sequence current is used as an identifier for stator winding faults of an induction motor. The fault detection scheme considers the imbalance in supply voltage and all inherent nonlinearity of the induction machine under investigation. This scheme utilizes the Power Decomposition Technique (PDT) to get the positive and negative sequence components of the supply voltage and currents. Although, this scheme is very efficient, it requires a large computation in extracting the positive and negative sequence components of the measured current and voltage signals. Furthermore, considerable calculations are used to compensate for the inherent nonlinearity (Arkan et al., 2001).

Corresponding Author: Bassim M.H. Jassim, Department of Electrical Engineering, College of Engineering, University of Baghdad, Jadria, Iraq, bassim.jassim@uob.edu.iq 
An immune method to variation in voltage unbalance, intrinsic asymmetry of the IM and measurement error is suggested (Lee et al., 2003). The coupling impedance between the negative and positive sequence circuits $Z_{n p}$ of the induction motor is used as an identifier of turn to turn fault which equals to zero in an ideal healthy machine. This approach requires the sequence components calculations for both line currents and voltages. Due to immunity of this method, no further computations are necessary to compensate for all the no idealities of the motor.

Based on the asymmetry admittance calculation, stator winding faults are diagnosed (Kato et al., 2014). The asymmetry admittance calculation can be achieved in two approaches. Either through calculation of negative sequence current component and the positive sequence voltage component of the park vector or adopting the knowledge of positive sequence admittance from the analysis or simulation along with negative and positive sequence current components of the current park vector. Therefore, the voltage measurement in the second approach is redundant. This proposal is effective in diagnoses the faults in one phase and several phases. But this approach assumes balanced supply voltage and requires an extensive mathematical process to extract the positive and negative sequence components of the voltage and current Park vectors.

This study presents a simple approach for inter-turn stator winding fault diagnosis where the ripple in the current space vector magnitude is used as a fault identifier. Therefore, minimal mathematical computations are necessary and the voltage imbalance may be considered easily.

Modelling of induction motor: To validate the proposal, a mathematical model for the healthy and faulty induction motor is developed using Coupled Circuit Approach (CCA) where the motor is represented by six magnetically coupled circuits (Ong, 1998).

Healthy induction motor model: Based on $\mathrm{dq} 0$ reference frame, the balanced sinusoidally distributed stator and rotor windings are represented by the following voltage equations:

$$
\begin{array}{r}
\mathrm{V}_{s}^{\mathrm{qd} 0}=i_{s}^{\mathrm{qd} 0} r_{s}^{\mathrm{qd} 0}+\left[\begin{array}{ccc}
0 & \omega & 0 \\
-\omega & 0 & 0 \\
0 & 0 & 0
\end{array}\right] \lambda_{s}^{\mathrm{qd} 0}+\frac{\mathrm{d}}{\mathrm{dt}} \lambda_{\mathrm{s}}^{\mathrm{qd} 0} \\
\mathrm{~V}_{\mathrm{r}}^{\mathrm{qd} 0}=i_{\mathrm{r}}^{\mathrm{qd} 0} r_{\mathrm{r}}^{\mathrm{qd} 0}+\left[\begin{array}{ccc}
0 & -\left(\omega-\omega_{\mathrm{r}}\right) & 0 \\
-\left(\omega-\omega_{\mathrm{r}}\right) & 0 & 0 \\
0 & 0 & 0
\end{array}\right] \lambda_{\mathrm{r}}^{\mathrm{qd} 0}+\frac{\mathrm{d}}{\mathrm{dt}} \lambda_{\mathrm{r}}^{\mathrm{qd} 0}
\end{array}
$$

where, $\quad \mathrm{V}_{\mathrm{s}}^{\mathrm{qda}}, \mathrm{V}_{\mathrm{r}}^{\mathrm{qda}}, \mathrm{i}_{\mathrm{s}}^{\mathrm{qda}}, \mathrm{i}_{\mathrm{s}}^{\mathrm{qda}}, \mathrm{r}_{\mathrm{s}}^{\mathrm{qda}}, \mathrm{r}_{\mathrm{f}}^{\mathrm{qda}}, \lambda_{\mathrm{s}}^{\mathrm{qda}}$ and $\lambda_{\mathrm{r}}^{\mathrm{dd} 0}$ are the matrices of stator voltage, rotor voltage, stator current, rotor current, stator resistance, rotor resistance, stator linkage flux and rotor linkage flux, respectively. The $\omega_{\mathrm{r}}$ in terms of rotor angle $\left(\theta_{\mathrm{r}}\right)$ and $\omega$ in terms of the angle between the q-axis and the a-axis in the abc frame $(\theta)$ are given as:

$$
\omega=\frac{\mathrm{d} \theta}{\mathrm{dt}}, \omega_{\mathrm{r}}=\frac{\mathrm{d} \theta_{\mathrm{r}}}{\mathrm{dt}}
$$

where, $\omega$ and $\omega_{\mathrm{r}}$ are the motor speed at arbitrary reference frame and rotor speed, respectively. The stator and rotor windings resistance matrices are defined as:

$$
\mathrm{r}_{s}^{\mathrm{qd} 0}=\left[\begin{array}{ccc}
\mathrm{r}_{\mathrm{s}} & 0 & 0 \\
0 & \mathrm{r}_{\mathrm{s}} & 0 \\
0 & 0 & \mathrm{r}_{\mathrm{s}}
\end{array}\right] ; \mathrm{r}_{\mathrm{r}}^{\mathrm{qd} 0}=\left[\begin{array}{ccc}
\mathrm{r}_{\mathrm{r}} & 0 & 0 \\
0 & \mathrm{r}_{\mathrm{r}} & 0 \\
0 & 0 & \mathrm{r}_{\mathrm{r}}
\end{array}\right]
$$

The linkage stator and rotor linkage flux in the dq0 frame are:

$$
\left[\begin{array}{c}
\lambda_{\mathrm{s}}^{\mathrm{qd} 0} \\
\lambda_{\mathrm{r}}^{\prime \mathrm{dd} 0}
\end{array}\right]=\left[\begin{array}{cccccc}
\mathrm{L}_{\mathrm{ss}}+\mathrm{L}_{\mathrm{m}} & 0 & 0 & \mathrm{~L}_{\mathrm{m}} & 0 & 0 \\
0 & \mathrm{~L}_{\mathrm{ls}}+\mathrm{L}_{\mathrm{m}} & 0 & 0 & \mathrm{~L}_{\mathrm{m}} & 0 \\
0 & 0 & \mathrm{~L}_{1 \mathrm{~s}} & 0 & 0 & 0 \\
\mathrm{~L}_{\mathrm{m}} & 0 & 0 & \mathrm{~L}_{\mathrm{lr}}+\mathrm{L}_{\mathrm{m}} & 0 & 0 \\
0 & \mathrm{~L}_{\mathrm{m}} & 0 & 0 & \mathrm{~L}_{\mathrm{lr}}+\mathrm{L}_{\mathrm{m}} & 0 \\
0 & 0 & 0 & 0 & 0 & \mathrm{~L}_{\mathrm{r}}
\end{array}\right]\left[\begin{array}{c}
\mathrm{i}_{\mathrm{s}}^{\mathrm{qd} 0} \\
\mathrm{i}_{\mathrm{r}}^{\prime \text { qd }}
\end{array}\right] \text { (4) }
$$

where, the stator and rotor leakage inductances for each phase are denoted by $\mathrm{L}_{1 s}$ and $\mathrm{L}_{\mathrm{l}}$, respectively. All parameters referred to the stator side are denoted with prime symbol. The torque and rotor speed equations are expressed as:

$$
\begin{gathered}
\mathrm{T}_{\mathrm{em}}=\frac{3}{2} \frac{\mathrm{p}}{2}\left(\lambda_{\mathrm{ds}} \mathrm{i}_{\mathrm{qs}}-\lambda_{\mathrm{qs}} \mathrm{i}_{\mathrm{ds}}\right) \\
\frac{\mathrm{d}\left(\omega_{r} / \omega_{\mathrm{b}}\right)}{\mathrm{dt}}=\frac{1}{2 \mathrm{H}}\left(\mathrm{T}_{\mathrm{em}}+\mathrm{T}_{10 \mathrm{ad}}-\mathrm{T}_{\mathrm{demp}}\right)
\end{gathered}
$$

where $\omega_{b}=2 \pi f$ is the base value of angular frequency of supply frequency $f$. The pole number is dented by $p$. The $\mathrm{T}_{\text {em }}, \mathrm{T}_{\text {load, }}, \mathrm{T}_{\text {damp }}$ and $\mathrm{H}$ are the electromagnetic torque, the mechanical torque of the load, damping torque and inertia constant, respectively.

Modelling of induction motor with inter-turn fault: The healthy motor model can be modified to cope with the inter-turn stator fault. This is obtained through introducing the proportion of healthy turns. Therefore, it is required to modify the inductance and resistance 
matrices (Bradley et al., 2014; Chen and Zivanovic, 2010). If $n_{s a}, n_{s b}$, and $n_{s c}$ represent the percentage of turns which have been shorted on the ' $a$ ', ' $b$ ', and ' $c$ ' stator windings, respectively, then the proportion of remaining healthy turns is given by:

$$
\begin{aligned}
& \mathrm{N}_{\mathrm{a}}=1-\mathrm{n}_{\mathrm{sa}} \\
& \mathrm{N}_{\mathrm{b}}=1-\mathrm{n}_{\mathrm{sb}} \\
& \mathrm{N}_{\mathrm{c}}=1-\mathrm{n}_{\mathrm{sc}}
\end{aligned}
$$

Assuming the short circuit occurs only in phase "a", and using abc to dq0 transformation, the $\mathrm{dq} 0$ resistance matrix is given as:

$$
r_{s}^{\mathrm{gd} 0}=r_{s}\left[\begin{array}{ccc}
r_{s_{1}} & 0 & r_{s 1_{3}} \\
0 & r_{s 2_{2}} & 0 \\
r_{s 3_{1}} & 0 & r_{s 3_{3}}
\end{array}\right]
$$

Where:

$$
\begin{aligned}
& \mathrm{r}_{\mathrm{s} 11}=\frac{1}{3}\left(2 \mathrm{~N}_{\mathrm{a}}+1\right), \mathrm{r}_{\mathrm{s} 13}=\frac{2}{3}\left(\mathrm{~N}_{\mathrm{a}}-1\right), \mathrm{r}_{\mathrm{s} 22}=1, \\
& \mathrm{r}_{\mathrm{s} 31}=\frac{1}{3}\left(\mathrm{~N}_{\mathrm{a}}-1\right), \mathrm{r}_{\mathrm{s} 33}=\frac{1}{3}\left(\mathrm{~N}_{\mathrm{a}}+1\right)
\end{aligned}
$$

Including the stator fault the flux linkage equation is given:

$$
\left[\begin{array}{l}
\lambda_{\mathrm{s}}^{\mathrm{qd} 0} \\
\lambda_{\mathrm{r}}^{\mathrm{qdd} 0}
\end{array}\right]=\left[\begin{array}{cccccc}
\mathrm{L}_{11} & 0 & \mathrm{~L}_{13} & \mathrm{~L}_{14} & 0 & 0 \\
0 & \mathrm{~L}_{22} & 0 & 0 & \mathrm{~L}_{25} & 0 \\
\mathrm{~L}_{31} & 0 & \mathrm{~L}_{33} & \mathrm{~L}_{34} & 0 & 0 \\
\mathrm{~L}_{41} & 0 & \mathrm{~L}_{43} & \mathrm{~L}_{44} & 0 & 0 \\
0 & \mathrm{~L}_{52} & 0 & 0 & \mathrm{~L}_{55} & 0 \\
0 & 0 & 0 & 0 & 0 & \mathrm{~L}_{66}
\end{array}\right]\left[\begin{array}{l}
\mathrm{i}_{\mathrm{s}}^{\mathrm{qd} 0} \\
\mathrm{i}_{\mathrm{r}}^{\mathrm{qd} d 0}
\end{array}\right]
$$

Where:

$$
\begin{gathered}
\mathrm{L}_{11}=\frac{1}{3}\left(2 \mathrm{~N}_{\mathrm{a}}^{2}+1\right) \mathrm{L}_{1 \mathrm{~s}}+\frac{1}{9}\left(2 \mathrm{~N}_{\mathrm{a}}+1\right)^{2} \mathrm{~L}_{\mathrm{m}} \\
\mathrm{L}_{13}=\frac{2}{3}\left(\mathrm{~N}_{\mathrm{a}}^{2}-1\right) \mathrm{L}_{1 \mathrm{~s}}+\frac{2}{9}\left(2 \mathrm{~N}_{\mathrm{a}}^{2}-\mathrm{N}_{\mathrm{a}}-1\right) \mathrm{L}_{\mathrm{m}} \\
\mathrm{L}_{14}=\mathrm{L}_{41}=\frac{1}{3}\left(2 \mathrm{~N}_{\mathrm{a}}^{2}+1\right) \mathrm{L}_{\mathrm{m}}, \mathrm{L}_{22}=\mathrm{L}_{1 \mathrm{~s}}+\mathrm{L}_{\mathrm{m}}, \mathrm{L}_{25}=\mathrm{L}_{52}=\mathrm{L}_{\mathrm{m}} \\
\mathrm{L}_{31}=\frac{1}{3}\left(\mathrm{~N}_{\mathrm{a}}^{2}-1\right) \mathrm{L}_{1 \mathrm{~s}}+\frac{2}{9}\left(2 \mathrm{~N}_{\mathrm{a}}^{2}-\mathrm{N}_{\mathrm{a}}-1\right) \mathrm{L}_{\mathrm{m}} \\
\mathrm{L}_{33}=\frac{1}{3}\left(\mathrm{~N}_{\mathrm{a}}^{2}+2\right) \mathrm{L}_{1 \mathrm{~s}}+\frac{2}{9}\left(\mathrm{~N}_{\mathrm{a}}^{2}-2 \mathrm{~N}_{\mathrm{a}}-1\right) \mathrm{L}_{\mathrm{m}} \\
\mathrm{L}_{34}=\frac{1}{2} \mathrm{~L}_{43}=\frac{1}{3}\left(\mathrm{~N}_{\mathrm{a}}-1\right) \mathrm{L}_{\mathrm{m}} \\
\mathrm{L}_{44}=\mathrm{L}_{55}=\mathrm{L}_{1 \mathrm{r}}^{\prime}+\mathrm{L}_{\mathrm{m}}, \mathrm{L}_{66}=\mathrm{L}_{1 \mathrm{r}}^{\prime}
\end{gathered}
$$

\section{MATERIALS AND METHODS}

Proposed method: In an ideal three phase induction motor, the three phase currents are balanced in a healthy condition and the current space vector magnitude $\left|I_{s}\right|$ calculated from Eq. 10 has only a dc component:

$$
\left|I_{s}\right|=\sqrt{\frac{2}{3}\left(i_{a}^{2}(t)+i_{b}^{2}(t)+i_{c}^{2}(t)\right)}
$$

Due to stator winding faults, imbalance supply voltage and inherent asymmetry in induction motor, the negative sequence components is generated and reflected as a ripple component in $\left|I_{s}\right|$ (Jassim et al., 2015). The following analysis shows that the ripple component proportional to the negative sequence current and can be used as a fault identifier. A balanced three phase currents with superimposed negative sequence component at fundamental frequency are expressed as:

$$
\begin{aligned}
& \mathrm{i}_{\mathrm{a}}(\mathrm{t})=\mathrm{I} \cdot \sin (\mathrm{wt})+\mathrm{K} \sin \omega t \\
& \mathrm{i}_{\mathrm{b}}(\mathrm{t})=\mathrm{I} \cdot \sin (\mathrm{wt}-2 \pi / 3)+\mathrm{K} \sin (\omega t-4 \pi / 3) \\
& \mathrm{i}_{c}(\mathrm{t})=\mathrm{I} \cdot \sin (\mathrm{wt}-4 \pi / 3)+\mathrm{K} \sin (\omega t-2 \pi / 3)
\end{aligned}
$$

Substituting Eq. 11 in Eq. 10 yields:

$$
\left|I_{s}\right|=\sqrt{\left(I^{2}+K^{2}-2 I K \cos 2 \omega t\right)}
$$

Equation 12 shows that negative sequence component at fundamental frequency is reflected as a ripple component in $\left|I_{s}\right|$ at twice the fundamental frequency. The existence of the ripple component $\frac{\pi \mathrm{I}_{s} \mid}{\mid \mathrm{I}_{\mathrm{s}}}$ can be used as a fault identifier and the ripple peak to peak value is proportional to fault severity. It is obvious that extraction of the negative sequence current in this proposal is simpler and more efficient in terms of the number of arithmetic operations than the previously mentioned methods.

The negative sequence current component may arise due the imbalanced supply voltage and this effect needs to be eliminated to obtain the negative sequence current due to inter-turn fault. The peak to peak of $\overline{[i}$ due to supply voltage imbalance, inter-turn fault and all causes

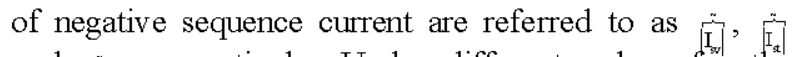
and $\overrightarrow{\left|I_{0}\right|}$, respectively. Under different values for the parameters include Voltage Unbalance Ratios (VUR) defined by Eq. 13, load levels and percentage inter-turn 
faults in the induction motor, the values $\ddot{\left[\mathrm{I}_{w}\right.}$, calculated. However, sequence voltage, since, the negative sequence impedance can be assumed constant regardless the load and the number of short-circuited turns (Kliman et al., 1996):

$$
\begin{gathered}
\text { Max. voltage desicrepency } \\
\text { VUR }=\frac{\text { from average phase voltage }}{\text { Average of phase voltages }} \times 100 \%
\end{gathered}
$$

The peak to peak value of $\ddot{[}$ is equal to $\overrightarrow{\mathrm{I}_{\mathrm{T}}}$ when the machine with $0 \%$ inter-turn fault (healthy motor), since, $\mid \overrightarrow{\mathbf{S}_{\infty} \mid}$ is given as:

$$
\tilde{\left|I_{s o}\right|}=\tilde{\mid I_{s v}}\left|+\tilde{\mid I_{s t}}\right|
$$

Using Eq. 14, the peak to peak value of calculated which can be used as identifier for the inter-turn fault severity.

\section{RESULTS AND DISCUSSION}

To examine the mathematical model of the induction motor developed in this study, a Simulink model is utilized to explore the stator current waveforms of the three-phase induction motor whose parameters listed in Table 1.

With unloaded motor, the Simulink model is examined under different motor conditions which are healthy motor

Table 1: Parameters of induction motor

\begin{tabular}{ll}
\hline Parameters & Values \\
\hline Output & $0.33 \mathrm{hp}$ \\
Voltage & $240 \mathrm{~V}, 50 \mathrm{~Hz}$ \\
Number of poles & 4 \\
Stator resistance & $17 \Omega$ \\
Rotor resistance & $15 \Omega$ \\
Stator leakage inductance $\mathrm{L}_{\text {is }}$ & $75.37 \mathrm{mH}$ \\
Rotor leakage inductance this $\mathrm{L}_{\text {ir }}$ referred or not & $75.37 \mathrm{mH}$ \\
Magnetizing inductance & $393.78 \mathrm{mH}$ \\
Number of turns per phase & 780 \\
\hline
\end{tabular}

and motor with $10 \%$ inter-turn fault. The stator currents of the healthy motor are balanced in terms of phase and magnitude (Fig. 1a). With 10\% inter-turn fault, the stator currents shown in Fig. $1 \mathrm{~b}$ are no longer balanced in phase and magnitude where the faulty phase has maximum peak to peak value.

The reflection of negative sequence component of stator currents in the magnitude of $\left|\mathrm{I}_{s}\right|$ is depicted in Fig. 2. Zero ripple component is observed in $\left|\mathrm{I}_{\mathrm{s}}\right|$ in a healthy motor while in a faulty motor, $\left|I_{s}\right|$ has a ripple component referred to as $\ddot{\left|I_{s}\right|}$ which is at twice the fundamental frequency with peak to peak value proportional to the fault severity. All these results confirm the mathematical analysis shown in Eq. $10-12$. Table 2-4 presents the peak to peak values of $\overrightarrow{\mathrm{I}_{\mathrm{v}} \mid}, \overrightarrow{\mathrm{I}_{\mathrm{s}}}$ and VUR, inter-turn fault severity and load levels. As assumed before, $\ddot{I_{\mathrm{I}}}$ is independent on the fault severity and load level.

The relationship between the negative sequence current components due to different reasons with fault severity is depicted in Fig. 3. The three negative sequence

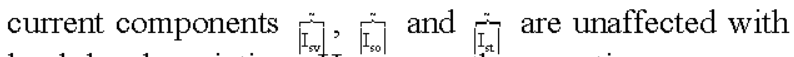
load level variation. However, the negative sequence current component due to inter-turn fault is increased with every rise in the number of short-circuited turns.

The effect of supply voltage imbalance on the inter-turn negative sequence current Fig. 4 where different VUR values are used to explore this effect. Figure 3 and 4 reflect the fact that inter-turn negative sequence current component $\overrightarrow{\left|I_{s t}\right|}$ is unrelated to the load level and the VUR value.

The negative sequence current component due to supply imbalance $\overrightarrow{\text { in }}$ vs. VUR values at different load levels is depicted in Fig. 5. It is evident, that the load level

\begin{tabular}{|c|c|c|c|c|c|c|c|c|c|}
\hline \multirow[b]{2}{*}{ Voltage imbalance (\%) } & \multirow{2}{*}{$\begin{array}{l}0 \% \text { fault } \\
-\tilde{\left|\mathrm{I}_{\mathrm{sv}}\right|} \mid=\tilde{\left|\mathrm{I}_{\mathrm{so}}\right|}\end{array}$} & \multicolumn{2}{|c|}{$2 \%$ fault } & \multicolumn{2}{|c|}{$5 \%$ fault } & \multicolumn{2}{|c|}{$8 \%$ fault } & \multicolumn{2}{|c|}{$10 \%$ fault } \\
\hline & & $\tilde{||_{s 0} \mid}$ & $\tilde{\left|I_{s t}\right|}$ & $\tilde{\left|\mathrm{I}_{80}\right|}$ & $\tilde{\left|I_{s t}\right|}$ & $\tilde{\left|I_{s 0}\right|}$ & $\tilde{\left|\tilde{I}_{\mathrm{so}}\right|}$ & $\tilde{\left|\mathrm{I}_{80}\right|}$ & ||$_{s t} \mid$ \\
\hline 0.0 & 0.0000 & 0.0366 & 0.0366 & 0.1027 & 0.1027 & 0.1857 & 0.1857 & 0.2529 & 0.2529 \\
\hline 0.6 & 0.0103 & 0.0472 & 0.0369 & 0.1137 & 0.1034 & 0.1973 & 0.1870 & 0.2650 & 0.2547 \\
\hline 1.3 & 0.0205 & 0.0577 & 0.0372 & 0.1247 & 0.1042 & 0.2089 & 0.1884 & 0.2770 & 0.2565 \\
\hline 1.9 & 0.0308 & 0.0682 & 0.0374 & 0.1357 & 0.1049 & 0.2205 & 0.1897 & 0.2891 & 0.2583 \\
\hline 2.6 & 0.0410 & 0.0787 & 0.0377 & 0.1467 & 0.1057 & 0.2321 & 0.1911 & 0.3012 & 0.2602 \\
\hline 3.2 & 0.0513 & 0.0893 & 0.0380 & 0.1577 & 0.1064 & 0.2437 & 0.1924 & 0.3132 & 0.2619 \\
\hline 3.9 & 0.0615 & 0.0998 & 0.0383 & 0.1687 & 0.1072 & 0.2553 & 0.1938 & 0.3253 & 0.2638 \\
\hline 4.5 & 0.0718 & 0.1103 & 0.0385 & 0.1797 & 0.1079 & 0.2669 & 0.1951 & 0.3374 & 0.2656 \\
\hline 5.1 & 0.0821 & 0.1208 & 0.0387 & 0.1907 & 0.1086 & 0.2785 & 0.1964 & 0.3494 & 0.2673 \\
\hline 5.8 & 0.0923 & 0.1314 & 0.0391 & 0.2018 & 0.1095 & 0.2901 & 0.1978 & 0.3615 & 0.2692 \\
\hline 6.4 & 0.1026 & 0.1419 & 0.0393 & 0.2128 & 0.1102 & 0.3017 & 0.1991 & 0.3736 & 0.2710 \\
\hline 7.0 & 0.1128 & 0.1524 & 0.0396 & 0.2238 & 0.1110 & 0.3133 & 0.2005 & 0.3856 & 0.2728 \\
\hline
\end{tabular}
has no effect on $\mid \overrightarrow{I_{\mathrm{s}}}$.

Table 2: Negative sequence current components under no load, different inter-turn fault and imbalanced supply voltage 


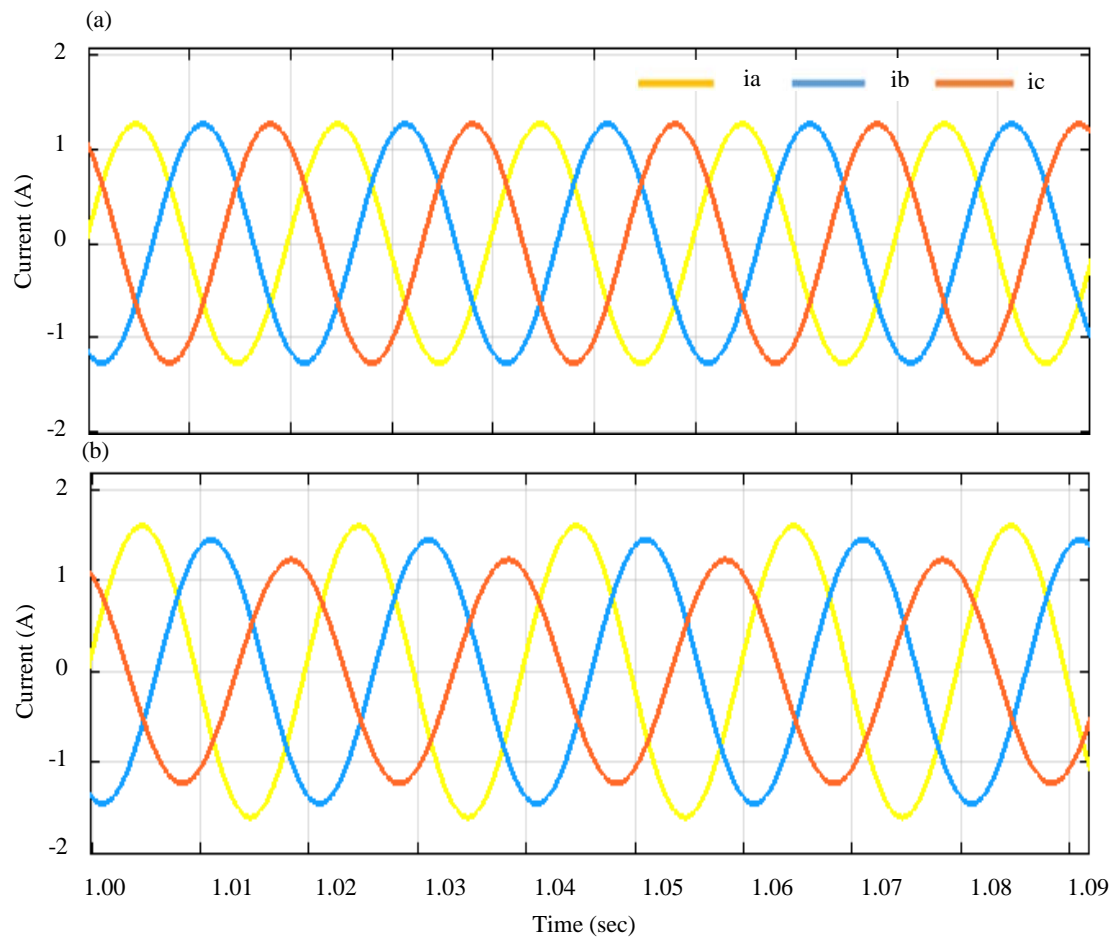

Fig. 1: Stator current waveforms: a) Healthy motor and b) Faulty motor with $10 \%$ inter-turn fault
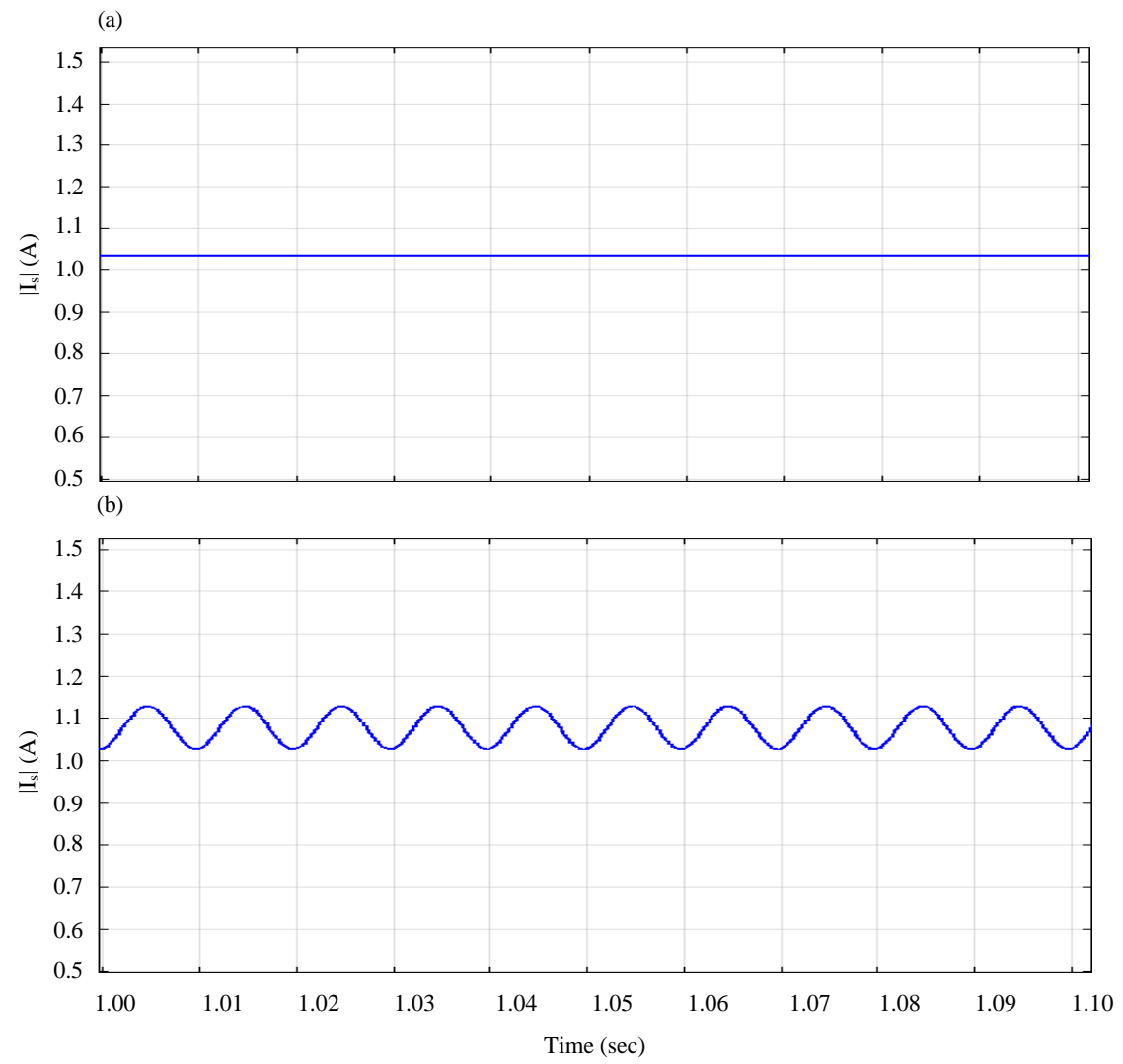

Fig. 2: Continue 


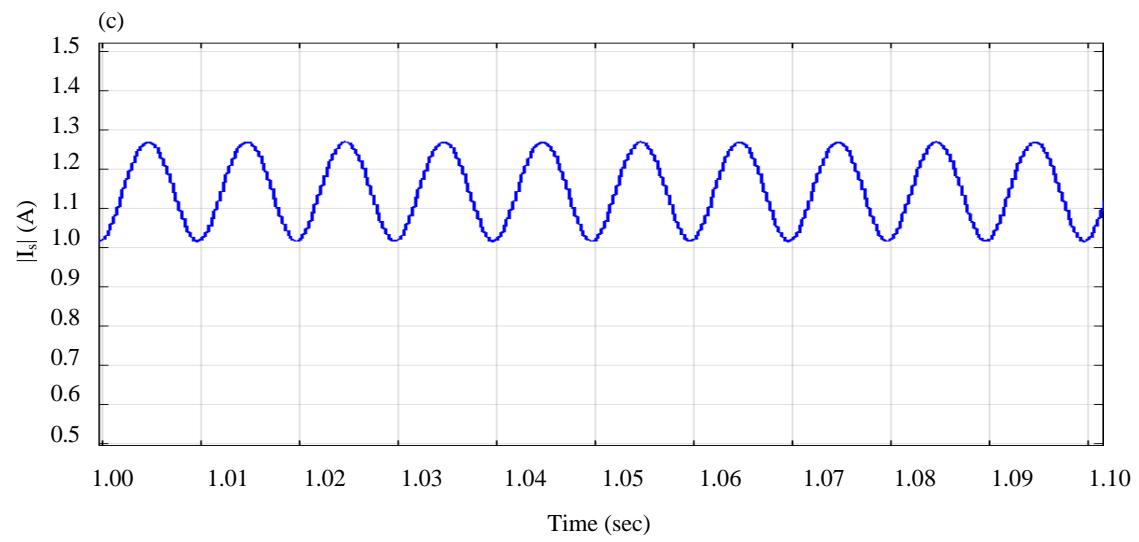

Fig. 2: Reflection of negative sequence component of stator current in $\left|\mathrm{I}_{\mathrm{s}}\right|$ : a) Healthy motor; b) Faulty motor with $5 \%$ inter-turn fault and c) Faulty motor with 10\% inter-turn fault

\begin{tabular}{|c|c|c|c|c|c|c|c|c|c|}
\hline \multirow[b]{2}{*}{ Voltage imbalance $(\%)$} & \multirow{2}{*}{\begin{tabular}{l}
$0 \%$ fault \\
\hdashline$\tilde{\mathrm{I}_{\mathrm{sV}}} \mid=\tilde{\left|\mathrm{I}_{\mathrm{so}}\right|}$
\end{tabular}} & \multicolumn{2}{|c|}{$2 \%$ fault } & \multicolumn{2}{|c|}{$5 \%$ fault } & \multicolumn{2}{|c|}{$8 \%$ fault } & \multicolumn{2}{|c|}{$10 \%$ fault } \\
\hline & & $\tilde{\left|\overrightarrow{I_{80}}\right|}$ & $\tilde{\left|\mathrm{I}_{\mathrm{st}}\right|}$ & $\tilde{\left|\overrightarrow{I_{s o}}\right|}$ & $\tilde{\left|\mathrm{I}_{\mathrm{st}}\right|}$ & $\tilde{\left|\mathrm{I}_{80}\right|}$ & $\left|\overrightarrow{I_{s t}}\right|$ & $\tilde{\left|\mathrm{I}_{80}\right|}$ & $\tilde{\left|\bar{I}_{s t}\right|}$ \\
\hline 0.0 & 0.0000 & 0.0366 & 0.0366 & 0.1025 & 0.1025 & 0.1851 & 0.1851 & 0.2520 & 0.2520 \\
\hline 0.6 & 0.0103 & 0.0471 & 0.0368 & 0.1135 & 0.1032 & 0.1967 & 0.1864 & 0.2641 & 0.2538 \\
\hline 1.3 & 0.0205 & 0.0576 & 0.0371 & 0.1245 & 0.1040 & 0.2083 & 0.1878 & 0.2761 & 0.2556 \\
\hline 1.9 & 0.0308 & 0.0681 & 0.0373 & 0.1355 & 0.1047 & 0.2199 & 0.1891 & 0.2882 & 0.2574 \\
\hline 2.6 & 0.0410 & 0.0786 & 0.0376 & 0.1465 & 0.1055 & 0.2315 & 0.1905 & 0.3002 & 0.2592 \\
\hline 3.2 & 0.0513 & 0.0892 & 0.0379 & 0.1575 & 0.1062 & 0.2431 & 0.1918 & 0.3123 & 0.2610 \\
\hline 3.9 & 0.0615 & 0.0997 & 0.0382 & 0.1685 & 0.1070 & 0.2547 & 0.1932 & 0.3244 & 0.2629 \\
\hline 4.5 & 0.0718 & 0.1102 & 0.0384 & 0.1795 & 0.1077 & 0.2663 & 0.1945 & 0.3364 & 0.2646 \\
\hline 5.1 & 0.0821 & 0.1207 & 0.0386 & 0.1905 & 0.1084 & 0.2779 & 0.1958 & 0.3485 & 0.2664 \\
\hline 5.8 & 0.0923 & 0.1313 & 0.0390 & 0.2015 & 0.1092 & 0.2895 & 0.1972 & 0.3606 & 0.2683 \\
\hline 6.4 & 0.1026 & 0.1418 & 0.0392 & 0.2125 & 0.1099 & 0.3011 & 0.1985 & 0.3726 & 0.2700 \\
\hline 7.0 & 0.1128 & 0.1523 & 0.0395 & 0.2235 & 0.1107 & 0.3126 & 0.1998 & 0.3847 & 0.2719 \\
\hline
\end{tabular}

Table 4: Negative sequence current components under level 2 load, different inter-turn fault and imbalanced supply voltage

\begin{tabular}{|c|c|c|c|c|c|c|c|c|c|}
\hline \multirow[b]{2}{*}{ Voltage imbalance $(\%)$} & \multirow{2}{*}{ 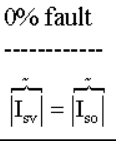 } & \multicolumn{2}{|c|}{$2 \%$ fault } & \multicolumn{2}{|c|}{$5 \%$ fault } & \multicolumn{2}{|c|}{$8 \%$ fault } & \multicolumn{2}{|c|}{$10 \%$ fault } \\
\hline & & $\tilde{\left|\overrightarrow{\mathrm{I}_{80}}\right|}$ & $\tilde{\left|\tilde{I}_{s t}\right|}$ & $\tilde{\left|\mathrm{I}_{30}\right|}$ & $\tilde{\left|\mathrm{I}_{s t}\right|}$ & $\tilde{\left|\mathrm{I}_{80}\right|}$ & $\tilde{\mid \overrightarrow{I_{s t}}} \mid$ & $\tilde{\left|\mathrm{I}_{80}\right|}$ & $\tilde{\left|I_{s t}\right|}$ \\
\hline$\overline{0.0}$ & 0.0000 & 0.0367 & 0.0367 & 0.1028 & 0.1028 & 0.1853 & 0.1853 & 0.2520 & 0.2520 \\
\hline 0.6 & 0.0103 & 0.0472 & 0.0369 & 0.1137 & 0.1034 & 0.1969 & 0.1866 & 0.2640 & 0.2537 \\
\hline 1.3 & 0.0205 & 0.0577 & 0.0372 & 0.1247 & 0.1042 & 0.2085 & 0.1880 & 0.2760 & 0.2555 \\
\hline 1.9 & 0.0308 & 0.0683 & 0.0375 & 0.1357 & 0.1049 & 0.2200 & 0.1892 & 0.2881 & 0.2573 \\
\hline 2.6 & 0.0410 & 0.0788 & 0.0378 & 0.1467 & 0.1057 & 0.2316 & 0.1906 & 0.3002 & 0.2592 \\
\hline 3.2 & 0.0513 & 0.0893 & 0.0380 & 0.1577 & 0.1064 & 0.2432 & 0.1919 & 0.3122 & 0.2609 \\
\hline 3.9 & 0.0615 & 0.0998 & 0.0383 & 0.1687 & 0.1072 & 0.2548 & 0.1933 & 0.3243 & 0.2628 \\
\hline 4.5 & 0.0718 & 0.1104 & 0.0386 & 0.1797 & 0.1079 & 0.2664 & 0.1946 & 0.3363 & 0.2645 \\
\hline 5.1 & 0.0821 & 0.1209 & 0.0388 & 0.1907 & 0.1086 & 0.2780 & 0.1959 & 0.3484 & 0.2663 \\
\hline 5.8 & 0.0923 & 0.1314 & 0.0391 & 0.2017 & 0.1094 & 0.2895 & 0.1972 & 0.3604 & 0.2681 \\
\hline 6.4 & 0.1026 & 0.1419 & 0.0393 & 0.2127 & 0.1101 & 0.3011 & 0.1985 & 0.3725 & 0.2699 \\
\hline 7.0 & 0.1128 & 0.1524 & 0.0396 & 0.2237 & 0.1109 & 0.3127 & 0.1999 & 0.3845 & 0.2717 \\
\hline
\end{tabular}

Based on the mentioned simulation data, the proposed approach to detect and diagnose the inter-turn fault may be implemented with the following three steps: acquisition of the three-phase induction motor input line currents and phase voltages.

Under any load level with the aid of Eq. 10, calculate Current Space Vector Magnitude (CSVM) of the acquired three-phase stator currents and the VUR value from Eq. 13. The fault detection phase is implemented through investigating the existence of ripple component in $\left|I_{s}\right|$ which is equal to $\overrightarrow{\left[\mathrm{I}_{\infty}\right]}$. If $\ddot{\left[\mathrm{I}_{\infty}\right]}$ is greater than $\overrightarrow{\left[\mathrm{I}_{w}\right.}$, then fault alarm will be issued with the existence of ripple component.

The fault location is specified in the phase which has maximum peak to peak current. Based on VUR value the is picked up from Fig. 5. Using Eq. 14, is calculated and then the fault severity can be specified $w i t h$ the aid of Fig. 4. 


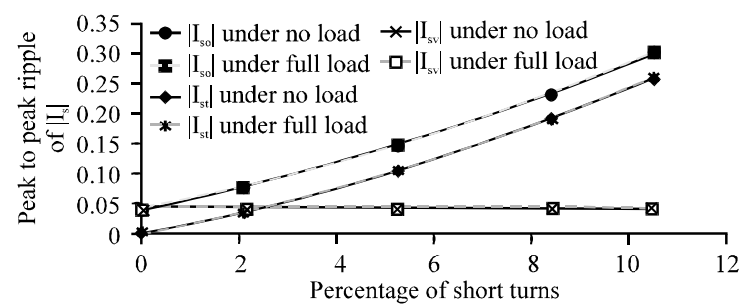

Fig. 3: Negative sequence current components vs. fault severity at VUR $=2.6 \%$ and for differsent load levels

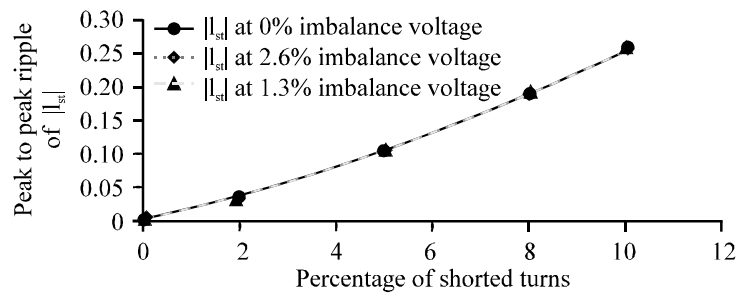

Fig. 4: Inter-turn negative sequence current component $\underset{\left(I_{\text {st }}\right)}{-}$ vs. fault severity under different VUR and level 2 load.

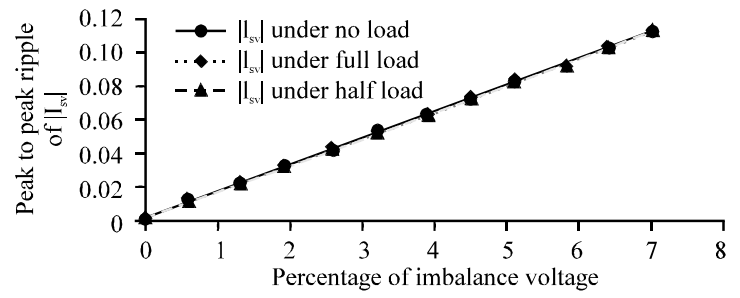

Fig. 5: Negative sequence current component $\sim$ vs. VUR under different load levels

\section{CONCLUSION}

A new approach for detection and diagnosis of inter-turn faults in three phase induction motor supplied from unbalanced voltage source is proposed. The negative sequence current component is used as a fault identifier to detect and diagnose the inter-turn fault in stator windings. Instead of conventional methods of negative sequence current component extraction, the reflection of negative sequence component as a ripple in the magnitude of current space vector is utilized. For this reason, the implementation of extraction the negative sequence current requires minimal computational burden. The value of the peak to peak ripple reflected in the current space vector magnitude is used as indicator to fault severity after elimination the effect of imbalanced voltage. The proposal simplicity and visibility are validated through developing a mathematical model three phase induction motor based on MATLAB/Simulink environment where the collected data from the model is used to characterize the motor.

\section{REFERENCES}

Abdallah, H. and K. Benatman, 2017. Stator winding inter-turn short-circuit detection in induction motors by parameter identification. IET. Electr. Power Appl., 11: 272-288.

Arkan, M., D.K. Perovic and P. Unsworth, 2001. Online stator fault diagnosis in induction motors. IEE Proc. Electr. Power Appl., 148: 537-547.

Bradley, W.J., M.K. Ebrahimi and M. Ehsani, 2014. A general approach for current-based condition monitoring of induction motors. J. Dyn. Syst. Meas. Control, 136: 1-12.

Chen, S. and R. Zivanovic, 2010. Modelling and simulation of stator and rotor fault conditions in induction machines for testing fault diagnostic techniques. Eur. Trans. Electr. Power, 20: 611-629.

Devi, N.R., D.S. Sarma and P.R. Rao, 2016. Diagnosis and classification of stator winding insulation faults on a three-phase induction motor using wavelet and MNN. IEEE. Trans. Dielectr. Electr. Insul., 23: 2543-2555.

Gandhi, A., T. Corrigan and L. Parsa, 2011. Recent advances in modeling and online detection of stator interturn faults in electrical motors. IEEE. Trans. Ind. Electron., 58: 1564-1575.

Jassim, B.M.H., D.J. Atkinson and B. Zahawi, 2015. Modular current sharing control scheme for parallel-connected converters. IEEE. Trans. Ind. Electron., 62: 887-897.

Kato, T., K. Inoue and K. Yoshida, 2014. Diagnosis of stator-winding-turn faults of induction motor by direct detection of negative sequence currents. Electr. Eng. Japn., 186: 75-84.

Kliman, G.B., W.J. Premerlani, R.A. Koegl and D. Hoeweler, 1996. A new approach to on-line turn fault detection in $\mathrm{AC}$ motors. Proc. IEEE Industry Appl. Annual Meeting, 1: 687-693.

Lee, S.B., R.M. Tallam and T.G. Habetler, 2003. A robust, on-line turn-fault detection technique for induction machines based on monitoring the sequence component impedance matrix. IEEE. Trans. Power Electron., 18: 865-872.

Ong, C.M., 1998. Dynamic Simulation of Electric Machinery: Using MATLAB/SIMULINK. Prentice Hall, Upper Saddle River, New Jersey, USA., ISBN-13:978-0137237852, Pages: 656. 
Prakasam, K. and S. Ramesh, 2016. Testing and analysis of induction motor electrical faults using current signature analysis. Circuits Syst., 7: 2651-2662.

Rodriguez, P.V. J. and A. Arkkio, 2008. Detection of stator winding fault in induction motor using fuzzy logic. Appl. Soft Comput., 8: 1112-1120.

Sharifi, R. and M. Ebrahimi, 2011. Detection of stator winding faults in induction motors using three-phase current monitoring. ISA. Trans., 50: 14-20.

Siddique, A., G.S. Yadava and B. Singh, 2005. A review of stator fault monitoring techniques of induction motors. IEEE Trans. Energy Convers., 20: 106-114.
Singh, G.K. and S.A.S. Al Kazzaz, 2003. Induction machine drive condition monitoring and diagnostic research-a survey. Electr. Power Syst. Res., 64: 145-158.

Thomson, W.T. and R.J. Gilmore, 2003. Motor current signature analysis to detect faults in induction motor drives-fundamentals, data interpretation and industrial case histories. Proceedings of the 32nd Symposium on Turbomachinery, September 8-11, 2003, Texas A\&M University, College Station, Texas, pp: 145-156.

Ukil, A., S. Chen and A. Andenna, 2011. Detection of stator short circuit faults in three-phase induction motors using motor current zero crossing instants. Electr. Power Syst. Res., 81: 1036-1044. 